\title{
Väestökysymystä, perhettä ja avioliittoa käsittelevää suomalaista kirjallisuutta vuosina 1948-1949.
}

Luetteloinut Helmi Nykänen.

Tähän bibliografiaan, joka muodostaa jatkon aikaisemmalle, Väestöliiton toisessa vuosikirjassa ilmestyneelle, sisältyy paitsi Suomessa painettuja itsenäisiä julkaisuja täällä ilmestyneiden tärkeimpien aikakauskirjojen ja -lehtien sekä kokoomateosten kirjoituksia, mutta ei sanomalehtiartikkeleita eikä kotimaisille kielille käännettyä kirịallisuutta. Saman kirjoittajan eri yhteyksissä julkaisemista samanlaisista kirjoituksista on vain yksi otettu huomioon.

Ajo, Reino, Riksplanering. Terra 1948, ss. 60-62.

- Valtakunnan suunnittelu. Porvoo-Helsinki 1948. $91 \mathrm{~s}$.

Allardt, Erik, Skärgårdens avfolkning. Ks. Svenska befolkningsförbundets i Finland r.f. publikationer.

Aura, Teuvo, Arava-lainat ja maalaiskunnat. Maalaiskunta 1949, ss. 260263.

- Asuntorakennustuotanto ja Arava-suunnitelma. Rakennustaito 1949, ss. 101-104, 113.

- Uuden valtion elimen perustaminen asuntotuotantoa edistämään. Suomen kunnallislehti 1948 , ss. $148-151$.

Axelson, Kaarina, Perheenäitien osapäivätyö lapsen kannalta katsottuna. Huoltaja 1948, ss. $185-188$.

Björkenheim, H., Maaseudun rakennusohjelmista. Maalaiskunta 1949, ss. 145-147.

Borg-Sundman, Margit, Koti ja yhteiskunta. Suomen nainen 1948, s. 36.

Brander, E.-Niemineva, K., Lääketieteellisistä syistä tehdyistä raskauden keskeyttämisistä. Duodecim 1949, ss. 479-510. 
Bäckström, Signe, Varför är husmödrarna överansträngda? Finlands röda kors 1948, ss. 114-115.

Böök, Einar, Suomen huolto-oikeus. Porvoo-Helsinki 1948. 370 s.

Ellilä, Tauno, Avioliittolain 81 §:n mukaisen muuttamismääräyksen täytäntöönpanosta. Defensor legis 1949, ss. 200-208.

Erkkilä, S., Sosiaalilääketiede yliopistollisena opetusaineena ja tieteellisen tutkimuksen kohteena. Suomen lääkärilehti 1948, ss. 435-444.

Eskola, Aarne, Maaseudun rakennusneuvonnan järjestely. Maalaiskunta 1949 , ss. $175-177$.

Fagerholm, K.-A., Suomalaista sosiaalipolitiikkaa. Sosiaalinen aikakauskirja 1949 , ss. $150-161$.

Fougstedt, Gunnar, Dödsorsakerna som demografiska faktorer. Väinö Kannisto: Kuolemansyyt väestöllisinä tekijöinä. Ekonomiska samfundets tidskrift, 3. ser, årg. 1 (1948), s. 55-57.

- Återväxten bland finlandssvenskarna. Finsk tidskrift 1949, t. 145 , ss. $55-$ 60.

Gripenberg, O., Asunnontuotannon hoidon keskittäminen. Tehostaja 1948, ss. $340-342$.

Gulin, E. G., Eronneitten vihkimisestä. Vartija 1949, ss. 49-55.

Gulin, E. G. \& Niemi, Turo, Avioliitto. Opaskirja Suomen kodeille. Helsinki 1949. $234 \mathrm{~s}$.

Haapanen, Sirkka, Ahtaitten asuntojen salaiset vaarat. Sosialistinen aikakauskirja 1949, ss. 241-244.

Hailuoto, Ahti, Oikea asuntopolitiikka - oikean kodin edellytys. Lapsi ja nuoriso 1948 , ss. $142-143,159$.

Hakulinen, Y. J., Muutettu avioliittolaki. Defensor legis 1948, ss. $300-321$, 333-371.

Harmaja, Leo, Heikki Waris: Suomalaisen yhteiskunnan rakenne. Kansantaloudellinen aikakauskirja 1948, ss. 271-274.

Harva, Urpo, Protestanttisen avioliittokäsityksen tarkastelua. Suomalainen Suomi 1949, ss. $184-188$.

Heikonen, A. R., Ilmari Melander: Asumusero. Lakimies 1949, ss. $345-349$. Heinonen, Lyyli, Vähävaraisten perheenäitien lomamahdollisuuksista. Huoltaja 1949 , ss. $93-97$.

Helasvuo, K., Lapset kotiapulaișina. Lapsi ja nuoriso $1949: 3-4$, ss. $1-3$, 14-15.

- Lapsilisän perspektiivejä. Lapsi ja nuoriso 1948, ss. 193, 209-210.

Henriksson, Weio, Arava-suunnitelma. Sosiaalinen aikakauskirja 1949, ss. 162-179.

- Asutuskeskusten yleishyödyllisen asuntotuotannon rahoitus. Suomen kunnallislehti 1948, ss. 151-154.

- Valtion asuntolainat, (Arava-lainat.) Helsinki 1949. 124 s. (Suomen lakimiesliiton kirjasarja 2.) 
- Valtion asuntolainat. (Arava-lainat.) 2. täyd. p. Helsinki 1949. 133 s.

- Vuokrat ja asuntotuotanto. Kansantaloudellinen aikakauskirja 1948, ss. 281-297.

Hertzen, Heikki v., Väestöpolitiikkamme päätapahtumat vuosina 1946-1948. Väestöliiton vuosikirja 2. Helsinki 1948. Ss. 219-240.

Hiisivaara-Mörk, Selma, Aitiysavustuslaki 10-vuotias. Tulevaisuus 1948, ss. $9,26$.

Hirvensalo, Mikko, Varhaiskuolleisuudesta. Duodecim 1949, ss. 645-652.

Huhtinen, Anja, Kymmenen vuotta äitiysavustuslain voimaantulosta. Kätilölehti 1948 , ss. $87-89$.

- Aitiys- ja lastenneuvolatyön suunnittelu. Kätílölehti 1948, ss. 178-180.

Hultin, Holger, Kiertävät lastenneuvolat. Suomen punainen risti 1948, s. 132 .

Huoltolait. Koonnut Sosiaaliministeriö. Helsinki 1949. $256 \mathrm{~s}$.

Huuskonen, Aarne, Koulujen kasvatusneuvonnasta. Kasvatusopillinen aikakauskirja 1948, ss. 78-90.

Hyppölä, Jorma, Tuomioistuimen päätöksellä puretut avioliitot vuosina 1945, 1946 ja 1947. Tilastokatsauksia 1949: $3-4$, ss. 34-37.

Hyvärinen, Kalle, Arava-lakien nojalla tapahtuva osuustoiminnallinen rakennustuotanto. Osuusliike 1949, ss. 93-94.

Härmä, Laura, Onko naisten asema työmarkkinoilla muuttumassa. Tulevaisuus $1948: 12$, ss. 28,43 .

Ihamuotila, Aune, Havaintoja Ruotsin kotitaloudesta. Emäntälehti 1949, ss. 198-201.

Isän kalenteri 1949 ja 1950. Julk. Väestöliitto. 'Helsinki 1948 ja 1949. Jalas, Rakel, Ansiotyö ja perheen emännyys. Suomen nainen 1949, ss. 142 144.

- Koti. Huoltaja 1948, ss. 185-187.

- Aitiysavustusta 10 vuotta. Suomen punainen risti 1948, ss. 4-5, 31-32. Jarle, Per-Olof, Den subventionerade bostadsproduktionen. Mercator 1949, ss. $634-635$.

Joensuu, Martti, Avioliitto-opetus ja kirkko. Vartija 1949, ss. 107-108. Jutikkala, Eino, Dudley Kirk: Europe's population in the interwar years. Kansantaloudellinen aikakauskirja 1948, ss. 68-75.

- Maaltapako jälleen. Suomalainen Suomi 1948, ss. 188-189.

- Väestöntutkimuksia. „Väestönpolitiikkamme uusia muotoja etsimässä». Väestöliiton vuosikirja 2, 1948. Suomalainen Suomi 1949, ss. 109-111.

- Yhteiskunta, johon kuulumme. Heikki Waris: Suomalaisen yhteiskunnan rakenne. Suomalainen Suomi 1948, ss. 98-101.

Kalha, J. E., Kihlaus ja avioliitto Suomen lain mukaan. Porvoo-Helsinki 1948. $150 \mathrm{~s}$.

Kalmari, Else, Kodinhoitaja - kotien ensi käden apu. Suomen punainen risti 1949 , ss. $18-19$. 
Kaltio, M. J., Onko muonamiesjärjestelmä elänyt aikansa? Maatalous 1948, ss. $23-25,38-39$.

Kaprio, Leo, Asuntokysymys lääkärih näkökulmasta. Rakennustaito 1949, ss. $347-349$.

- Synnytysavun annosta Yhdysvalloissa. Kätilölehti 1949, ss. 282-284.

- Yhteiskunnallisesta keskenmenotorjunnasta. Suomen lääkärilehti 1949, ss. $111-114$.

Kaprio, Leo A. \& Rouhunkoski, Mauri, On the marriage guidance clinics in Finland. Helsinki 1949. Ss. 224-234. (Annales chirurgiae et gynaecologiae Fenniae. Vol. 38, suppl. 3.)

Karttunen, Sievä, Kotitalousopetus ja koulunuudistus. Kasvatusopillinen aikakauskirja 1949, ss. 200-208.

Keravuori, Keijo (toim.) Teollisuuden sosiaalinen toiminta. HeIsinki 1948. $371 \mathrm{~s}$. (Suomen työnantajain keskusliiton julkaisuja.)

Kivinen, Pentti, Rakennustoiminta vuosina 1943-1948. Suomen Pankin taloustieteellisen tutkimuslaitoksen julkaisuja, sarja A: 9, ss. 28-58.

Knoellinger, Carl Erik, Vår samhällsstruktur. Heikki Waris: Suomalaisen yhteiskunnan rakenne. Ekonomiska samfundets tidskrift, 3. ser, årg. 1 (1948), ss. 103-110.

Komiteanmietintö 1948:2. Väestörekisterikomitean mietintö. Helsinki 1948. $92 \mathrm{~s}$.

- 1948: 9. Komiteanmietintö naimisissa olevien naisten ansiotyöstä. Helsinki 1949. $62 \mathrm{~s}$.

- 1949: 7. Huolto-ohjelmakomitean mietintö. Helsinki 1949. $165 \mathrm{~s}$.

Koskikallio, Margit, Avioton äitiys. Kirj. M. K-llio. Lapsi ja nuoriso 1949: 11, ss. $23-24$.

- Avioton äitiys erään tutkimuksen valossa. Kirj. K-llio. Lapsi ja nuoriso 1949: 10, ss. 25-27.

- Aviottoman äidin persoonalliset edellytykset lapsensa kasvattajana. Lapsi ja nuoriso 1949: 12 , ss. 21-22.

Kotilainen, Niilo, Lastensuojelutyöstä Amerikan Yhdysvalloissa. Huoltaja 1949 , ss. $67-70,231-238$.

Kovero, Martti, Ruotsi-Suomen taulustolaitoksen syntyhistoriaa. Kansantaloudellinen aikakauskirja 1948, ss. 26-43.

Lagerqvist, Ulla \& Niemineva, Kalevi, Huomioita kuukausittaisesta syntyneisyydestä Suomessa. Duodecim 1949, ss. 602-614.

Lainvalmistelukunnan julkaisuja 1948:1. Ehdotus hallituksen esitykseksi eduskunnalle laiksi raskaudentilan keskeyttämisestä. Helsinki 1948. $42 \mathrm{~s}$.

- 1949: 4. Ehdotus hallituksen esitykseksi eduskunnalle laiksi avioliittolain 4 \&:n muuttamisesta. Helsinki 1949. $3 \mathrm{~s}$.

Lappalainen, Veijo, Aitiysavustuslain muutos. Sosiaalinen aikakauskirja 1949, ss. $387-390$.

Lappi-Seppälä, Jussi, Asuntokysymyksestä. Valvoja 1949, ss. 97-99. 
- Asuntorakennustoiminnan elvyttäminen. Rakennustaito 1948, ss. 295-296. Larma, Otto, Maaseudun uusi rakennuslainsäädäntö selitettynä. Hämeenlinna 1949. $133 \mathrm{~s}$.

Larsson, Sixten, Ruotsin asuntopolitiikan suuntaviivoja. Maalaiskunta 1949, ss. $60-63$.

Laukas, Arvo, Suurteollisuutemme työväestön asuntokysymys. Rakennustaito 1949 , ss. $339-342$.

Lehti, Helmer, Työväen asunto-olot ja niiden kehittäminen. Tehostaja 1948, ss. $342-346$.

Leino, Jouko, Eronneitten vihkimisasia. Vartija 1949, ss. 62-64.

Leivo-Larsson, Tyyne, Ansioäidin ongelmia. Tulevaisuus 1948: 6, ss. 14-15, 35.

- Lastensuojelun ajankohtaisia kysymyksiä. Suomen kunnallislehti 1949, ss. $176-179,198$.

Lento, Reino, Mitä on väestötiede? Väestöliiton vuosikirja 2, ss. 183-189.

- Muuttoliikkeestä ja sen syistä eräissä Kuopion läänin kunnissa vuosina 1921-1944. Väestöliiton vuosikirja 2, ss. 99-147. Ks. myös Väestöpoliittisen tutkimuslaitoksen julkaisuja, sarja A: 2.

- Ranskan ja Belgian perhepalkkausjärjestelmät. Väestöliiton vuosikirja 2, ss. $69-88$.

— Väestötieteellinen tutkimustyö ja sitä suorittavat laitokset meillä ja muualla. Väestöliiton vuosikirja 2, ss. 190-206.

Lento, Sirkka. Ks. Haapanen, Sirkka.

Leon-Lindh, K., Tanskan Punaisen Ristin äitien lomakoti. Suomen punainen risti 1948, ss. 153-154, 179.

Leppo, Erkki, Ensimmäinen täydellinen kansainvälinen äitiys- ja lastenhuoltotyön ohjelma laadittu. Terveydenhoitolehti 1949, ss. 144-145.

- Katsaus Suomen Kunnallisen Terveydenhoitoyhdistyksen 10-vuotiseen toimintaan. Terveydenhoitolehti 1948, ss. 70-73.

- Suomen äitiys- ja lastenhuolto sekä aborttikysymys ja kouluterveydenhoito. Terveydenhoitolehti 1949, ss. 20-22.

- Aitiysneuvola - suuri sosiaalinen edistysaskel. Tulevaisuus 1948: 7-8, ss. $7,32$.

Lindahl, Erik, Några principiella synpunkter på den moderna socialpolitiken. Ekonomiska samfundets tidskrift, 3. ser., årg. 1 (1948), ss. 16-27.

Lindeberg, Ernst, Maaseudun asunto-olojen parantaminen. Asutustoiminnan aikakauskirja 1948, ss. 10-13.

Liukkonen, $R$., Muistelmia Helsingin lastensuojelun alkutaipaleelta. Huoltaja 1949 , ss. $102-106,152-155,172-174$.

Luostarinen, Aino, Mitä kunta voi tehdä maalaisnaisen aseman helpottamiseksi. Maalaiskunta 1948, ss. 71-72.

Löyskä, Toivo, Maaseudun keskusrakennustoimiston suuntaviivoista. Maalaiskunta 1949 , ss. $340-341$. 
Mannio, Niilo A., Sosiaalisen turvallisuuden järjestelmä. Huoltaja 1949, ss. 283-287.

Melander, Ilmari, Asumusero. Porvoo-Helsinki 1949. 181 s. (Suomalaisen lakimiesyhdistyksen julkaisuja, B-sarja 38.)

- Eräitä avioliiton ulkopuolella syntyneen lapsen oikeudellisen aseman parantamista koskevia kysymyksiä. Lakimies 1948, ss. 176-185.

Melander, Sylvi, Särkyneet kodit ongelmalasten muovaajina. Lapsi ja nuoriso 1948 , ss. $10-12$.

Merikoski, V., Luentoja huolto-oikeudesta. [Helsinki] 1948. 169 s. (Suomalaisen lakimiesyhdistyksen julkaisuja, B-sarja 31.)

Meurman, Otto-I., Omakoti asuntomuotona. Rakennustaito 1949, ss. 281-284.

- Suuria epäkohtia maaseudun rakennustoiminnassa. Talouselämä 1948, ss. $917-918$.

Modeen, G., Byggnadsverksamheten och dess framtidsutsikter. Mercator 1948, s. 259.

- Byggnadsvolymen i tätorterna år 1948. Mercator 1949, ss. 187-188.

- En lärobok i svensk socialpolitik. Åke Elmér: Svensk socialpolitik. Ekonomiska samfundets tidskrift, 3. ser., årg. 2 (1949), ss. 43-45.

- Fastighetskostnader och hyresnivå. Ekonomiska samfundets tidskrift, 3. ser., årg. 2 (1949), ss. $19-39$.

- Maaseudun uusi rakennustuotantotilasto. Maalaiskunta 1949, ss. 530-531.

- Vår byggnadspolitik. Mercator 1949, ss. 779-780.

Muilu, Martti, Eräiden teollisuuskeskustemme väestön hedelmällisyydestä. Suomalainen Suomi 1948, ss. 276-278.

Mustala, Paavo, Voimassa olevan lainsäädännön edellyttämä vanhusten huolto. Sosiaalinen aikakauskirja 1949, ss. 11-19.

- Vähävaraisten äitien kesävirkistys. Huoltaja 1949, ss. 150-151.

Mäenpää, Jorma, sItsestään selvääs vaiko sliian vaikeatas? Perhekasvatus kouluissa luo pohjan kotien uudistumiselle. Tulevaisuus 1948: 10, ss. 4-5.

- Väestöliiton avioliittoneuvontatyö. Kirj. J. M. Huoltaja 1948, ss. 303-304.

- Väestöliiton kotisisartoiminta. Kirj. J. M. Huoltaja 1948, ss. 285-286.

- Väestöliitto. Kirj. J. M. Huoltaja 1948, ss. 257-259.

Mäkelä, Aaro, Ensimmäisen suuruusluokan sosiaalinen kysymys. Sosialistinen aikakauslehti 1948 , ss. 192-195.

Mäkinen-Ollinen, Aune, Aitiyssuojelusuunnitelmat. Huoltaja 1949, ss. 195 -200 .

Nieminen, Armas, Kuopion läänin perhelisäperheistä ja niiden asunto- ym. oloista. Väestöliiton vuosikirja 2, ss. 148-180. Ks. myös Väestöpoliittisen tutkimuslaitoksen julkaisuja, sarja A: 3 .

- Mihin suuntaan perhe nykyaikaisessa kaupunkilaistuvassa yhteiskunnassa on kehittymässä? Amerikkalaista perhesosiologista tutkimusta. Väestöliiton vuosikirja 2, ss. 207-218. 
- Piirteitä perhepalkkauksen kehityksestä Sveitsissä. Väestöliiton vuosikirja 2, ss. 89-96.

- Yleisen lapsilisäjärjestelmän synty Ruotsissa ja Norjassa. Väestöliiton vuosikirja 2, ss. $32-68$.

Niemineva, K., Väestöliiton neuvolatoiminnasta. Kätilölehti 1948, ss. $63-66$. Nurminen, Elli, Kodin demokratia. Tulevaisuus 1949: 12, ss. 12-13, 42.

Nykänen, Helmi, Väestökysymystä, perhettä ịa avioliittoa käsittelevää suomalaista kirjallisuutta vuosina 1941-1947. Väestöliiton vuosikirja 2, ss. $241-256$.

Nikkilä, Yrjö, Synnytyssairaalat - valtion unohtama sairaalamuoto. Suomen kunnallislehti 1948, ss. 136-137.

Paloheimo, Martti, Voidaanko avioliittoja auttaa? Vartija 1949, ss. 180-183. Pesola, Vilho A., Avioliiton ja avioeron probleemeja. Valvoja 1949, ss. 9-17.

- Kahdeksas perinnöllisyystieteen kansainvälinen konferenssi. Valvoja 1948, ss. $194-197$.

Pipping, Hugo E., Socialpolitiska principfrågor. F. Zeuthen: Social Sikring (Socialpolitik, II Bd.) Ekonomiska samfundets tidskrift, 3. ser., årg. 2 (1949), ss. 101-107.

Pirjola, Kosti, Tietoja eräistä lastensuojelun työmuodoista vuodelta 1948. Kirj. K. P. Huoltaja 1949, ss. 115-117.

Pohjolainen, Heikki, Huolto- ja lastensuojelunäkökohtien vaarinottamisesta lastentarhatoiminnassa. Huoltaja 1949, ss. 210-212.

Poikolainen, Ahti, Kunnanlääkärin näkemyksiä ja kokemuksia äitiysneuvolatyöstä. Kätilölehti 1948 , ss. 110-117.

Procopé, Victor, Nationalekonomiska och finanspolitiska synpunkter på den förflyttade befolkningens ersättningsproblem. Ekonomiska samfundets tidskrift, 3. ser., årg. 2 (1949), ss. 138-172.

- Riksplaneringen stampar på stället. Mercator 1949, ss. 71-72.

Ranta, Jaakko, Tuberkuloosikuolleisuudesta Suomessa. Duodecim 1949, ss. 335-348.

Rantamaa, Antti, Onnellinen avioliitto. 2. uud. ja lisätty p. Helsinki 1948. $76 \mathrm{~s}$.

Rautiala, Martti, Avioeron varalta tehtyjen sopimusten sitovaisuudesta. Defensor legis 1949, ss. 23-38.

- Avioliitto-oikeus. Turku 1948. 357 s. (Suomalaisen lakimiesyhdistyksen julkaisuja, B-sarja 30 .)

- Suomen avioliittolainsäädäntö pääpiirteissään. Porvoo-Helsinki 1948. 120 s. (Aikamme kulttuuri 10.)

Rauttamo, Mari, Terve, elinvoimainen yhteiskunta Väestöliiton tavoitteena. Suomen punainen risti 1949, ss. 4-5, 21.

Reenkola, Mies, Kätilö ja kansanterveys. Kätilölehti 1948, ss. 28-31.

- Suvunjatkaminen aikamme kuvastimessa. Porvoo-Helsinki 1948. 274 s. 
Reinilä, E. J., Uusi työmuoto: Ensimmäisen suomenkielisen kuntainyhtymän kasvatusneuvola Tampereella. Suomen punainen risti 1949, ss. 48, 63-64. Reitz, Lauri, Asuntotuotanto. Rakennustaito 1949, ss. 121-123.

Rouhunkoski, Mauri, Abortit - kansamme häpeä. Terveydenhoitolehti 1948, ss. $190-191$.

- David R. Mace: Marriage counselling. Duodecim 1949, ss. 813-814.

— Ei enää tahallisia keskenmenoja. Terveydenhoitolehti 1948, ss. 100-101.

- Miksi avioliitot särkyvät. Terveydenhoitolehti 1949, ss. 209-211.

- Miten USA valmistaa nuorisonsa perhe-elämään. Lapsi ja nuoriso 1949: 10, ss. 7-10.

- Preventiivitekniikasta. Duodecim 1949, ss. 674-676.

- Sukupuolikasvatus ja syntyväisyyssäännöstely avio- ja perheonnen tekijöinä. Mielisairaanhoitaja 1949, ss. 14-16.

- Syntyvyyden säännöstelyn opas. Ks. Väestöliiton julkaisuja 25.

— Syntyvyyssäännöstelystä. Suomen lääkärilehti 1948 , ss. $577-581$.

- Aiti, toiko haikara minutkin? Tulevaisuus 1949: 2, ss. 16-17, 24.

Saarenheimo, Eero, Alkoholismi ja väestökysymys Ranskassa. Alkoholikysymys 1948 , ss. $81-90$.

- Ranskan väestöpulma. Kansantaloudellinen aikakauskirja 1949, ss. 162 -172 .

- Siirtolaisuus Italian sosiaalipolitiikan pulmana. Sosialistinen aikakauslehti 1949 , ss. $162-165$.

- Väkijuomien käyttö ja kuolleisuuden mieshakuisuus Suomessa ja Ranskassa. Alkoholikysymys 1949, ss. 129-133.

Saari, Erkki, Avioerolasten mahdollisuus joutua pahantapaisuuden tielle suurempi kuin muiden lasten. Lapsi ja nuoriso 1948, ss. 36-38.

Sahlan, Inkeri, Kotiapulaislaki. Sosiaalinen aikakauskirja 1948, ss. $371-374$.

- Kotien työvoimapula. Kotiapulaistyökomitean toinen mietintö. Sosiaalinen aikakauskirja 1948 , ss. $15-24$.

- Uusi kotiapulaislakimme. Suomen nainen 1949 , ss. 3-4, 6-7.

Salmela-Järvinen, Martta, Aidin palkka - onko sitä maksettava ja kuka sen maksaa? Tulevaisuus 1948: 6, ss. 6, 21.

Salmiala, Bruno, Lẩäkärin vastuu naisen suostumuksin tapahtuneen rikollisen sikiönlähdettämisen yhteydessä naiselle aiheutetusta kuolemasta tai vaikeasta ruumiinvammasta. Defensor legis 1949, ss. 101-115.

Saloheimo, Aksel, Xitiyshuollon kehityksestä ja suuntaviivoista maassamme. Kätilölehti 1949 , ss. $35-45$.

Saloheimo, Helvi, Havaintoja valvonta- ja neuvontatyön mahdollisuuksista perhelisän täydentäjänä. Huoltaja 1949 , ss. 528-529.

Salomaa, Niilo, Perhelisät vv. 1945-1946. Sosiaalinen aikakauskirja 1948, ss. $172-175$.

- Perhelisät v. 1947. Sosiaalinen aikakauskirja 1949, ss. 264-266. 
Sarlin, Bruno, Alaikäiset kotiapulaiset. Kirj. B. S. Huoltaja 1949, ss. 147149.

- Sosiaalipolitiikan piriin kuuluvien reformien toteuttamisohjelma. Huoltaja 1949, ss. 91-93.

Saurio, Elli, Miten paljon aikaa menee kodin hoitamiseen? Emäntälehti 1949, ss. $14-15,36-38,62-64,92-94,141-143,166-168,194-197,222-224$, 255-257, 286-288.

Schantz, Monica von, Sexualhygieni i USA. Finlands röda kors 1948, ss. $60-$ $61,66$.

Setkänen, Heikki, Kuntien asuntotuotannon edistämiseen välittämät lainat. Maalaiskunta 1949, ss. $423-426$.

Setälä, Antero, Kärkölän kunnan asunto-oloista. Duodecim 1949, ss. 524-538.

- Viimeaikaisesta kuolevuudesta ja työkyvyttömyydestä Suomessa. Duodecim 1948, ss. $530-535$.

Sillanpää, Miina, Kotiapulaisten ihmisarvoa kohotettu. Tulevaisuus 1949: 1, ss. $20-21,24$.

Simonen, Aarre, Suuri sosiaalinen uudistus - yleinen lapsilisä - toteutumassa. Tulevaisuus 1948: 3, ss. 4-5.

Smeds, Helmer, Europas befolkningsutveckling. Dudley Kirk: Europe's population in the interwar years. Ekonomiska samfundets tidskrift, 3. ser., årg. 1 (1948), ss. 274-278.

Social legislation and work in Finland. Publ. by the Ministry for Social Affairs. Helsinki 1949. $179 \mathrm{~s}$.

Solin, Lauri, Väestörekisterikomitean mietintö. Vartija 1948, ss. 138-141.

Sosiaalinen lainsäädäntö ja toiminta Suomessa. [Julk.] Sosiaaliministeriö. Helsinki 1949. $139 \mathrm{~s}$.

Sorvari, Matti, Asuntotuotannon elvyttäminen. Rakennustaito 1948, ss. 119 -120 .

Stählberg, Aune, Kesä ja lapset. Huoltaja 1949, ss. 76-77.

Sukselainen, V. J., Suomen lapsilisäjärjestelmä. Väestöliiton vuosikirja 2, ss. $9-31$.

Sumu, Aku, Perhelisä - lapsilisä. Sosialistinen aikakauslehti 1948, ss. 5-7. Suomen tilastollinen vuosikirja 1946-48, Uusi sarja 43-44. Helsinki 1948 - 49.

Suomen virallinen tilasto VI. Väestötilastoa A 101, B 102. Helsinki 1949.

Suominen, Y. K., Kastroimislaki- ja -asetusehdotuksesta. Suomen lääkärilehti 1948 , ss. $569-576$.

Surakka, Pirkko, Naimisissa olevien naisten ansiotyö. Sosiaalinen aikakauskirja 1948, ss. 225-234.

Suurpä̈̈, K., Kunnanlääkärin kokemuksia äitiysneuvolatyöstä maalla. Kätilölehti 1948 , ss. $139-145$.

Svenska befolkningsförbundets i Finland r.f. publikation 8. Svenska befolkningsförbundet i Finland r.f. 1947. Helsingfors 1948. 15 s.

- 9. Allardt, Erik, Skärgårdens avfolkning. Helsingfors 1948. 16 s. 
- 10. Svenska befolkningsförbundet i Finland r.f. 1948. Helsingfors 1949. $14 \mathrm{~s}$.

Tabeller beskrivande den stationära befolkningen i Finland och Sverige enligt förhållandena åren 1936-40. Ekonomiska samfundets tidskrift, 3. ser., årg. 1 (1948), ss. 173-202.

Tarasti, Aarne, Einar Böök: Suomen huolto-oikeus. Lakimies 1948, ss. 697700.

- Kodinhoitoapu sosiaalisena työmuotona. Huoltaja 1948, ss. 49-53.

- Lapsen elatusavun turvaaminen. Sosiaalinen aikakauskirja 1949, ss. 1-10.

- V. Merikoski: Luentoja huolta-oikeudesta. Lakimies 1949, ss. 77-81.

Temari, Y., Luettelo Suomen sosiaalisesta lainsäädännöstä. 3. p. Helsinki 1949. 89 s. (Sosiaaliministeriön julkaisuja. Sarja: Sosiaalisia käsikirjoja.)

Thylin, Henning, Ruotsin uusi asuntopolitiikka. Sosialistinen aikakauslehti 1948, ss. $221-223$.

Timonen, Sakari, Subjektiivisesta aborttimotivaatiosta. Suomen lääkärilehti 1949, ss. $101-110$.

Tirinen, Arvo, Arava-suunnitelman toteuttaminen v. 1949. Sosiaalinen aikakauskirja 1949, ss. 326-329.

- Ensimmäisen Arava-vuoden saavutukset numeroiden valossa. Suomen kunnallislehti 1949, ss. 180-181, 198.

Toftegaard, Jens, Asuntotuotanto ja sen rahoitus Tanskassa. Kansantaloudellinen aikakauskirja 1948 , ss. 10-25.

Tunkelo, A., Lisääntyneet avioerot ja niiden seuraukset. Lapsi ja nuoriso 1948 , ss. $3-5$.

- Vanhukset väestöllisenä tekijänä. Geron 1, ss. 5-14.

— Väestöliitto, Väestöpolitiikkamme uusia muotoja etsimässä. Väestöliiton vuosikirja. Kansantaloudellinen aikakauskirja 1949, ss. 263-264.

- Väestömme rakenne viime vuosikymmeninä ja sen kehitys lähitulevaisuudessa. Kansantaloudellinen aikakauskirja 1949, ss. 204-220.

- Väestönmuutokset vuonna 1947. Tilastokatsauksia 1949: 5-6, ss. 32-40.

Tuominen, O. A., Ruotsin asuntopolitiikkaa. Sosiaalinen aikakauskirja 1949, ss. $62-64$.

Turunen, Aarno, Terve ja sairas sukupuolielämä. Vartija 1948, ss. 76-83.

Tuukkanen, Väinö, Eräitä asemakaavallisia näkökohtia maaseudun rakentamisessa. Maalaiskunta 1949, ss. 274-276.

Törnqvist, Leo, En befolkningsstatistisk jämförelse mellan Finland och Sverige. Ekonomiska samfundets tidskrift, 3. ser., årg. 1 (1948), ss. 139-171. Uggla, John, Den nya abortlagstiftningen. Finsk tidskrift 1948, t. 143, ss. 154-164.

Waismaa, Usko, Lapsilisälaki. Sosiaalinen aikakauskirja 1948, ss. 217-224.

- Yleinen lapsilisä toteutumassa. Lapsi ja nuoriso 1948, ss. 71-73.

Valvanne, Leena, Väestöliiton sosiaalineuvolatyöstä. Huoltaja 1949, ss. 204205. 
Waris, Heikki, Einar Böök, Suomen huolto-oikeus. Kansantaloudellinen aikakauskirja 1948, ss. 269-271.

- Suomalaisen yhteiskunnan rakenne. Helsinki 1948. $368 \mathrm{~s}$.

- Uusia yhteyksiä - uusia tutkimustehtäviä. Suomalainen Suomi 1949, ss. $475-481$.

Vehaskari, Allan, On sterility in Finnish women with special reference to its causes and prognosis. Helsinki 1948. $123 \mathrm{~s}$.

Verkkosalo, Hilkka, Vähän ottolapsista ja yleisön suhtautumisesta adoptioon. Huoltaja 1949, ss. $170-172$.

Wiherheimo, Onni, Valtakunnansuunnittelu. Sosialistinen aikakauslehti 1948, ss. $226-227$.

Vihma, Väinö, Kihlauksen purkautumisesta. Lakimies 1948, ss. 29-55.

Viro, Voitto, Avioliittolain muutokset. Vartija 1948, ss. 173-175.

Väestöliiton julkaisuja 22. Vuoden 1948 perhelisätarvikkeita. Ohjekirjasen „Perhelisälain toimeenpano» lisälehti n:o 6. Helsinki 1948. $19 \mathrm{~s}$.

- 23. Toukokuun toinen sunnuntai. Aitienpäiväohjelmistoa 8. Helsinki 1948. $31 \mathrm{~s}$.

- Vuoden 1949 perhelisätarvikkeita. Ohjekirjasen »Perhelisälain toimeenpanos lisälehti n:o 7. Helsinki 1949. $23 \mathrm{~s}$.

- 25. Rouhunkoski, Mauri, Syntyvyyden säännöstelyn opas. 2. p. Helsinki 1949. $48 \mathrm{~s}$.

Väestöliiton vuosikirja 2. Väestöpolitiikkamme uusia muotoja etsimässä. Helsinki 1948. $256 \mathrm{~s}$.

Väestöpoliittisen tutkimuslaitoksen julkaisuja. Sarja A: 2. Lento, Reino, Muuttoliikkeestä ja sen syistä eräissä Kuopion läänin kunnissa vuosina 1921-1944. Helsinki $1948.57 \mathrm{~s}$.

- A: 3. Nieminen, Armas, Kuopion läänin perhelisäperheistä ja niiden asunto- ym. oloista. Helsinki 1948. $41 \mathrm{~s}$.

Väestöpolitiikkamme uusia muotoja etsimässä. Ks. Väestöliiton vuosikirja 2. Väkevien voimien pyörteissä. Mitä on terve rakkaus- ja sukuelämä. Helsinki 1948. $102 \mathrm{~s}$.

Aidin kalenteri 1949 ja 1950. Julk. Väestöliitto. Helsinki 1948 ja 1949.

Aitiysavustukset v. 1946. Sosiaalinen aikakauskirja 1948, ss. 389-390.

- v. 1947. Sosiaalinen aikakauskirja 1949, ss. 401-402. 